\title{
Statistical Assessment of Employee's Turnover and Its Causes; In the Case of Moret and Jiru Wereda, North Shoa, Amhara, Ethiopia
}

\author{
Natnael Mamuye \\ Department of Statistics, College of Natural and Computational Science, Debre Berhan University, Debre Berhan, Ethiopia \\ Email address: \\ naty.buna@gmail.com \\ To cite this article: \\ Natnael Mamuye. Statistical Assessment of Employee's Turnover and Its Causes; In the Case of Moret and Jiru Wereda, North Shoa, \\ Amhara, Ethiopia. American Journal of Theoretical and Applied Statistics. Vol. 7, No. 4, 2018, pp. 139-146. \\ doi: 10.11648/j.ajtas.20180704.12
}

Received: March 17, 2018; Accepted: March 30, 2018; Published: May 3, 2018

\begin{abstract}
The purpose of this study is to assess the employee turnover rate and cause in the case of Moret and Jiru Wereda. In light of this objective the study adopted quantitative and qualitative method of research approaches to test a series research hypothesis and subjective analysis respectively. Specifically, the study used survey of questionnaire analysis of Moret and Jiru Wereda. 326 respondents were selected based on stratified random sampling method. Data was then analyzed on quantitative basis using binary logistic regression and descriptive statistics; however, qualitative basis was used to subjective data. The result of this paper indicates that among the respondents $39.9 \%$ of them do not want to quit their current job but majority of them $(60.1 \%)$ said they seriously consider quitting their job very often. And furthermore the logistic regression found that Age of respondent, income of the respondents, experience of the respondents, educational level, satisfaction and incentive to be significantly related with turnover intension of the respondents and other factors such as gender, working hour and stress are found to be insignificant predictors of the turnover intension of the employees.
\end{abstract}

Keywords: Moret and Jiru Wereda, Turnover Intension, Logistic Regression

\section{Introduction}

The workforce or labor force is a group within the organization that is undeniably one of the most important factions that contributes to its success. A business cannot exist without both financial and human capital [1]. It is the employees who work for the company, performs necessary task to make the organizational function and are responsible for the profit and growth of the organization [1].

Human Resource Managers in organization go through time consuming and expensive process to mobilize workforce for the organization. It is estimated that the costs associated with recruiting and training a new employee average between half and one and a half times the annual salary for the post in question, depending on the approaches [2]. Human Resource Managers therefore seek ways to reduce the time and money spent on trying to ensure that people choose not to leave an organization voluntarily in the first place. Labor turnover rates vary in the Moret and Jiru
Wereda from sector to sector. Results from the Wereda survey (2008) indicate that the aggregate rate of labor turnover for the Moret and Jiru was 16 percent.

Negatively, employee turnover has the potential to reduce the quality of the organizational service. This is usually the case when labor force is reduced and the same amount of work is left for fewer hands to do so. This is find the work too much for the remaining employees and in trying to do more work than they used to do since they usually do not have a choice but to do a poor job. Besides, the effects of turnover are reflected at the time when employee leaves an organization because the employee takes with his/her knowledge and experience that which cannot be monetarily measured and that cannot be easily recreated [3]. Positively, turnover can be advantageous to the organization in that it provides an opportunity to replace less productive employees with new energetic people who ready to work, inject new blood in the organization veins and motivate the employee who takes the position of the leaving staff [2]. 
At national level, in Ethiopia, employee turnover in the public sector appears not have been extensively researched and documented especially in Wereda case the problem is severe there. However, employee turnover studies were conducted in Ethiopia by the researchers on different sectors. For example, Asmamaw [4] explores the professional employees' turnover and retention practice in Ethiopian public sector and organization of ministries of finance and economic development. A research was conducted on staff turnover in international Non-Governmental Organizations (NGOs) a case study of International Rescue Committee (IRC) by Yared [5]. Solomon [6] also conducted a research on skilled manpower turnover and its management in the case of Ethiopian road authority. A turnover issue in the textile industry in Ethiopia in a case of Arba Minch Textile Company was also studied by Kumar [7].

Considering of the above facts investigated by various researchers, organization should understand why their employees leave and stay to mitigate the reason of leaving the organization and the reason staying in the organization to attract other competent employees from the market and achieve the going concern of the organization. Therefore, there is a clear need to develop a better understanding of employee turnover and more specifically the rate in which they leave the organization per year and causes that are key indicators of why employees leave the organization which would then have a profound impact on the strategies that managers can employ in order to reduce employee turnover within their organizations [8]. According to Ongori [9] the value of employees to an organization is a very crucial element in organizations success. This value is intangible and cannot be easily replicated; therefore, it becomes very important that managers should control employee turnover for the benefit of the organization.

\section{Statement of the Problem}

Moret and Jiru Wereda is one of the districts or Wereda that are found in North Shoa Zone. This Wereda currently has a total of 1,756 employees. To be the right public service provider, the Wereda should maintained adequate number of the right sort of employees with appropriate training, qualifications and experience who serve its customers as per the rules and regulation of the Ethiopian public sector. Indeed, its effective performance depends not only on the available technical resources, but also on the quality and competence of its employees as required by the sector from time to time. Boxall and Purcell propose that organizations would have invested heavily into developing these employees who hold critical knowledge and skill. Additionally, human capital is neither widely accessible nor easily imitated [10].

The major causes of employee's turnover were identified through carried out different studies with retentions strategies that organizations should follow by various researchers $[9,3$ and 7]. These studies were carried out in different countries and organizations. According to the results of these researches, turnover causes may vary from countries to countries since those countries may be categorized under developing or developed countries [11]. Beside the countries, the organization sectors the study were conducted may be the factor to the turnover causes. [11] Also stressed how culture plays a role in the causes of individual withdrawal within organizations. Though several studies were addressing the cause of employee turnover in other industries;

i. Very little has been done to address the causes and rate of employee turnover in public sectors specifically on the lower Wereda case.

ii. Most of the studies have not applied advanced statistical model like logistic regression model

iii. The number of employees leaving their job in Moret and Jiru Wereda is increasing from time to time as shown in the following table.(source Moret and Jiru Wereda administration )

Table 1. The number of employees leaving their job from 2006-2008 Ethiopian calendar.

\begin{tabular}{llll}
\hline \multirow{2}{*}{ Sex } & Year & & \\
\cline { 2 - 4 } & $\mathbf{2 0 0 6}$ & $\mathbf{2 0 0 7}$ & $\mathbf{2 0 0 8}$ \\
\hline Male & 48 & 88 & 93 \\
Female & 40 & 39 & 52 \\
Total & 88 & 127 & 141 \\
\hline
\end{tabular}

Research Questions

The researcher is guided by some of these research questions to complete the work.

i. What are the determinant factors of turnover rate in Moret and Jiru Wereda?

ii. What are the impacts of employee turnover on the quality of the public sector service provision?

Objectives of the Study

The main objective of the study is to assess the employee turnover rate and cause in the case of Moret and Jiru Wereda.

The specific objectives of this research are:

i. To identify the factors that lead to the employee's turnover in Moret and Jiru Wereda.

ii. To assess the magnitude and nature of employee turnover.

iii. To assess the impact of turnover intension on the overall performance of the organization

\section{Methods}

\subsection{Sampling Design}

\subsubsection{Target Population}

Population refers to the entire group of people, events, or things that the researcher wishes to investigate [12]. The organizations that have been targeted are all public offices that are found in Moret and Jiru Wereda. Especially, employees of 25 sectors' that are found in the respective Wereda are target population of the study.

\subsubsection{Sampling Technique and Sample Size Determination}

The researcher use a probabilistic sampling design in order to create equal chance of being selected as a respondent for all employees. Among the probability sampling methods, stratified sampling technique is going to be employed in order to draw proportional samples from all Pools sector offices. Moreover, individual respondent has been selected from each stratum by 
using simple random probability sampling method. The populations are grouped to four (4) strata based on the present day governmental office grouping or pooling system.

Table 2. Total population based on stratum.

\begin{tabular}{lll}
\hline No of stratum & Name of pool & Numbers of employees \\
\hline 1 & Agriculture pool & 196 \\
2 & Administration pool & 193 \\
3 & Communication pool & 103 \\
4 & Civil Service pool & 1264 \\
Grand total & & 1756 \\
\hline
\end{tabular}

In conducting a research study, it is practically impossible, time-consuming and too expensive to test every individual in the entire population. Therefore smaller chunks of a unit sample are chosen to represent the relevant attributes of the whole of the units [13].

The researcher has used rationale of the total population to determine the sample size formula;-

$$
\begin{gathered}
n=\frac{N}{1+N\left(e^{2}\right)} \\
\text { where } n=\text { total sample size. } \\
E=\text { error }[0.05] \\
N=\text { total population. } \\
n=1756 /(1+1756(0.05) 2)=326
\end{gathered}
$$

Finally 326 respondents have been selected from the total population. The sample size is proportionally taken from each stratum as shown in the following table.

Table 3. The sample size taken from each sectors.

\begin{tabular}{llll}
\hline $\begin{array}{l}\text { No of } \\
\text { stratum }\end{array}$ & Name of pool & $\begin{array}{l}\text { Numbers of } \\
\text { employees }\end{array}$ & $\begin{array}{l}\text { Sample size } \\
(\mathbf{1 0 \% )}\end{array}$ \\
\hline 1 & Agriculture pool & 196 & 36 \\
2 & administration pool & 193 & 36 \\
3 & Communication pool & 103 & 19 \\
4 & Civil Service pool & 1264 & 235 \\
\multicolumn{2}{l}{ Grand total } & 1756 & 326 \\
\hline
\end{tabular}

\subsection{Data Collection Technique}

In this study, data will be primarily collected through the utilization of questionnaires and interview and secondary data has been also used which was obtained from the Wereda administration office.

\subsection{Data Analysis Technique}

Descriptive statistics data analysis method is going to be applied to analyze quantitative data where data is scored by calculating the number and percentages and inferential methods also used to model the relationship between the dependent variable and independent variables. Qualitative data analysis method is also be employed to analyze qualitative data gathered using the interview check list and documents from the sectors.

Descriptive Statistics

Descriptive statistics utilizes numerical and graphical method to look for patterns in the data set, summarize the information related in a data set and to present the information in a convenient or meaningful form. For this study descriptive method such as frequency distribution table, proportion, were used to summaries the most important features of the sample data.

\section{Inferential statistics}

The objective of statistical inferences is to make conclusion about a population based on the information obtained from the sample. Since population is characterized by numerical descriptive measures called parameter, statistical analysis is concerned with making inference about population parameter based on results obtained from the sample statistic. From different type of inferential statistics this paper has used binary logistic regression analysis.

\section{Results}

In this chapter the results of this study is presented in two main sections. In the first section the results of the descriptive statistics for the sampled respondents are presented. The result of the of the binary logistic regression is presented in the second section.

Socio-demographic characteristics of the respondents

A sample survey of 306 respondents from Moret and Jiru Wereda is collected to achieve the main objective of this study. The table shows that there are more male respondents $(72.2 \%)$ than female respondents $(27.8 \%)$. The respondents age ranges from 18 to 60 with $30-45$ category consist of the majority of them $(57.8 \%)$. Educational charactersitics of the respondents shows that the majority i.e $50.8 \%$ have bacholor degree and only $6.9 \%$ have masters degree. Interms of experiance, only $8.8 \%$ have experiance above 30 years and $7.2 \%$ of them have experiance less than one year. In general out of 306 respondents, $17 \%$ of them in a position and the $\operatorname{rest}(83 \%)$ are ordinary workers.

Table 4. Demographic characteristics of the samples.

\begin{tabular}{llll}
\hline Variables & Categories & Frequency & Percent \\
\hline \multirow{4}{*}{ Age } & $18-29$ & 90 & 29.4 \\
gender & $30-45$ & 177 & 57.8 \\
& $46-60$ & 39 & 12.7 \\
& male & 221 & 72.2 \\
Experience & female & 85 & 27.8 \\
& Below 1 year & 22 & 7.2 \\
& $1-10$ years & 131 & 42.8 \\
Position & 11-20 years & 92 & 30.1 \\
& 21-30 years & 34 & 11.1 \\
& Above 30 years & 27 & 8.8 \\
Educational level & managers & 52 & 17 \\
& Non managers & 254 & 83 \\
& Certificate & 52 & 16.7 \\
& Diploma & 79 & 25.8 \\
& Degree & 155 & 50.7 \\
& masters & 21 & 6.9 \\
& Below 1500 birr & 22 & 7.2 \\
& 1501-2500 birr & 50 & 16.3 \\
& 2501-3500 birr & 88 & 28.8 \\
& 3501-4000 birr & 32 & 10.5 \\
& 4001-5000 birr & 58 & 19 \\
& Above 5000 birr & 56 & 18.3 \\
\hline
\end{tabular}


Turnover intension of employees

The employees turn over intension is meaured by asking respondents whether they often seriously consider leaving their current job. The next table shows the percentage of respondents in moret and jiru wereda that are categorized in each level of turn over intension. When respondents were asked about it, about $39.9 \%$ of them said no and the rest about $60.15 \%$ of them said yes.

Table 5. Descriptive statistics of turn over intension of the respondents.

\begin{tabular}{llll}
\hline Attributes & categories & Frequency & Percent \\
\hline I often seriously & no & 122 & 39.9 \\
consider leaving my & yes & 184 & 60.1 \\
current job & Total & 306 & 100.0 \\
\hline
\end{tabular}

\section{Agreement level of attributes}

Respondents agreement level with each attributes in terms of percentage are shown in the table below. Respondents offered a 5 point likert scale ranging from 1 which represents 'strongly disagree' to 5 which represent 'strongly agree' to measure their level of agreement for each attribute. As shown in the table, among the respondents, $41.2 \%$ of them replied strongly agree to the statement that states Job satisfaction influence the employee turn ever rate in public sector. And only $2.3 \%$ of the respondents were neutral to the same statement. On the other hand about $15 \%$ of the respondents believe that job satisfaction effectively implemented their office. The minimum percent occur when respondents reply their agreement level on whether qualification and experience are considered for promotion and the opportunity are equal to other employees or not. Only $1 \%$ of the employees strongly agreed to the statement.

Satisfaction attributes

Table 6. The satisfaction attributes of the respondents.

\begin{tabular}{|c|c|c|c|c|c|}
\hline \multirow{2}{*}{ Satisfaction Attributes } & \multicolumn{5}{|c|}{ Level of agreement (\%) } \\
\hline & strongly disagree & disagree & neutral & agree & strongly agree \\
\hline Job satisfaction influence the employee turn ever rate in public sector & 12.7 & 31.7 & 2.3 & 12.1 & 41.2 \\
\hline job satisfaction effectively implemented our office & 15.0 & 24.5 & 17.3 & 39.5 & 3.6 \\
\hline My job has good promotion and have the ability to grow in my job & 18.0 & 23.5 & 18.6 & 34.3 & 5.6 \\
\hline I feel secured in my job & 39.2 & 30.7 & 4.9 & 13.1 & 12.1 \\
\hline $\begin{array}{l}\text { The sector gives enough recognition for well done work and I feel } \\
\text { appreciated at work }\end{array}$ & 11.4 & 15.7 & 22.2 & 43.1 & 7.5 \\
\hline $\begin{array}{l}\text { my qualification and experience are considered for promotion and the } \\
\text { opportunity are equal to other employees }\end{array}$ & 19.6 & 19.3 & 21.6 & 38.6 & 1.0 \\
\hline
\end{tabular}

The table below presents the percent of respondents for each category to statements related to stress. Accordingly among all respondents, $17.6 \%$ of the respondents strongly disagree to the statement "job stress affected the employee turnover rate in public sector". And about $14.1 \%$ of the respondents strongly disagree to the statement which states that job stress problem stands from staff leaders. I

Stress attributes

Table 7. The stress attributes of the employees.

\begin{tabular}{|c|c|c|c|c|c|}
\hline \multirow{2}{*}{ Stress Attributes } & \multicolumn{5}{|c|}{ Level of agreement (\%) } \\
\hline & strongly disagree & disagree & neutral & agree & strongly agree \\
\hline job stress affected the employee turnover rate in public sector & 17.6 & 28.1 & 10.8 & 39.5 & 3.9 \\
\hline job stress problem stands from staff leaders & 14.1 & 19.0 & 12.7 & 52.0 & 2.3 \\
\hline work stress problem stands from employee itself & 9.2 & 17.0 & 15.4 & 56.5 & 2.0 \\
\hline
\end{tabular}

The next table is about questions related to working hour. Based on the result, we observe that about $66.6 \%$ of the respondents are neutral to the statement "short working hours the best to reduce high turnover rate". Surprisingly only $2.3 \%$ of the respondents strongly believe that long working hours affect the employee turn ever rate in public sector.

Working hour attributes

Table 8. The working hour attributes of the respondents.

\begin{tabular}{|c|c|c|c|c|c|}
\hline \multirow{2}{*}{ Working hour Attributes } & \multicolumn{5}{|c|}{ Level of agreement (\%) } \\
\hline & strongly disagree & disagree & neutral & agree & strongly agree \\
\hline Long working hours affect the employee turn ever rate in public sector & 12.1 & 12.7 & 18.6 & 54.2 & 2.3 \\
\hline short working hours the best to reduce high turnover rate & 9.2 & 20.9 & 66.7 & 3.3 & 9.2 \\
\hline
\end{tabular}

Regarding to incentive, the respondent's response is summarized in the next table. Accordingly among all respondents; about $34.3 \%$ of the respondents strongly believe that wage /salary/ incentive schemes affect the attitude of employee. As expected, only $4.6 \%$ of the respondents strongly disagree to the statement which state that moral incentive schemes can higher work attitude of employee. And about $38.9 \%$ of the respondents believe that the incentive schemes affect the attitude of employee. From qualitative part we observe that, the migration of the workers is due to the fact that they don't get different motivational things, they don't have initiation to perform their job. They stay there until they get good chance.

Incentive attributes 
Table 9. The incentive attributes of the employees.

\begin{tabular}{llllll}
\hline \multirow{2}{*}{ Incentive Attributes } & \multicolumn{2}{l}{ Level of agreement (\%) } & & \\
\cline { 2 - 5 } & strongly disagree & disagree & neutral & agree & strongly agree \\
\hline the incentive schemes affect the attitude of employee & 3.6 & 26.5 & 12.4 & 18.6 & 38.9 \\
moral incentive schemes can higher work attitude of employee & 4.6 & 34.6 & 7.2 & 11.8 & 41.8 \\
Wage /salary/ incentive schemes affect the attitude of employee & 3.9 & 26.1 & 7.8 & 27.8 & 34.3 \\
\hline
\end{tabular}

The final table related to attributes is statements related to reward and the finds are briefly presented below. About $68 \%$ of the respondents strongly believe that career growth can motivate employee working in public sector. Only $1.6 \%$ of the respondents strongly dis-agrees to the above statements. While $32.4 \%$ of the respondents believe that certification standard more advantages another types of motivation system, only $2.3 \%$ of the respondents disagree to the same statements. Finally $64.6 \%$ of the respondents strongly agree that staff leaders must give moral appreciates for their employees and only $3.9 \%$ of the respondents are neutral to this statement.

\section{Reward attributes}

Table 10. The reward attributes of the employees.

\begin{tabular}{|c|c|c|c|c|c|}
\hline \multirow{2}{*}{ Reward Attributes } & \multicolumn{5}{|c|}{ Level of agreement (\%) } \\
\hline & strongly disagree & disagree & neutral & agree & strongly agree \\
\hline career growth can motivate employee working in public sector & 1.6 & 24.2 & 2.9 & 3.3 & 68 \\
\hline certification standard more advantages another types of motivation system & 2.3 & 34.3 & 6.5 & 24.5 & 32.4 \\
\hline staff leaders must give moral appreciates for their employees & 1.6 & 28.8 & 3.9 & 1.6 & 64.6 \\
\hline
\end{tabular}

The relation between turn over intension and different attributes

Binary logistic regression is applied to assess the relationship between turn over intension which is dichotomized response variable (yes /no) and sociodemographic characteristics and different attributes. SPSS version 20 is used to perform binary logistic regression by making "no" level as reference category. Before applying the final multiple logistic regression models with the given covariates for the intended purpose it has to be assessed and diagnosed for all possible model inadequacies.

Table 11. Variables in the Equation for the relationship between turn over intension and covariates.

\begin{tabular}{|c|c|c|c|c|c|c|}
\hline Covariates & B & S.E. & Wald & $\begin{array}{l}\text { Degree of } \\
\text { freedom }\end{array}$ & p-value & $\operatorname{Exp}(B)$ \\
\hline Gender(female ) & .577 & .462 & 1.557 & 1 & .212 & 1.781 \\
\hline Age(18-29 years) & -1.522 & .760 & 4.014 & 1 & .045 & .218 \\
\hline Age $(30-45$ years $)$ & -.534 & .725 & .544 & 1 & .461 & .586 \\
\hline Experience (below 1 year) & -1.374 & 1.579 & .757 & 1 & .384 & .253 \\
\hline Experience (1-10 year) & 2.816 & .811 & 12.066 & 1 & .001 & 16.706 \\
\hline Experience (11-20 year) & 2.663 & .841 & 10.036 & 1 & .002 & 14.338 \\
\hline Title( managers) & -1.283 & .565 & 5.161 & 1 & .023 & .277 \\
\hline Education & 1.528 & .313 & 23.900 & 1 & .000 & 4.610 \\
\hline Income(below 1500 birr) & 2.426 & 1.085 & 4.994 & 1 & .025 & 11.310 \\
\hline Income(1501-2500 birr) & 2.496 & .730 & 11.706 & 1 & .001 & 12.135 \\
\hline Income(2501-3500 birr) & 1.538 & .544 & 7.996 & 1 & .005 & 4.657 \\
\hline Income(3501-4000 birr) & .943 & .694 & 1.845 & 1 & .174 & 2.568 \\
\hline Income(4000-5000 birr) & -.762 & .603 & 1.599 & 1 & .206 & .467 \\
\hline Working hour & .527 & .328 & 2.592 & 1 & .107 & 1.694 \\
\hline reward & .002 & .348 & .000 & 1 & .995 & 1.002 \\
\hline incentive & .508 & .250 & 4.144 & 1 & .042 & 1.663 \\
\hline satisfaction & -.855 & .286 & 8.919 & 1 & .003 & .425 \\
\hline Constant & -5.827 & 2.252 & 6.697 & 1 & .010 & .003 \\
\hline
\end{tabular}

In the Variable Equation table, factors such as age, educational level, income, experience, position, satisfaction and incentive score are significant at $5 \%$ level of significance. And other factors such as gender, reward, working hour and stress are not statistically related with turnover intension. Note that Exp (B) gives the odds ratios for each variable.

The coefficient of age (18-29 years) is negative indicating that respondents from this group are less likely to quit their job than respondents from the reference group (above 45). But there is no statistically significant difference between the age category $30-45$ years and above 45 years. And the coefficient of satisfaction score is also negative indicating that the more satisfied the respondents are in the working environment; the less likely they are to quit their job. That is for a unit increase in the score of satisfaction, the probability of quitting the job lowers by 0.435 on average.

The coefficient of Experience (1-10 year) is positive which 
can be interpreted as respondent which have experience from 1 to 10 years are more likely to quit their job than respondents which have experience more than 30 years. And also the coefficient of experience (11-20) is positive which also indicates respondents from this group are more likely to quit their job than respondents from the reference group (above 30). But no statistical difference is observed between respondents which have less than 1 year experience and respondents that have above 30 years' experience.

The associated coefficient of education is positive indicating that as the educational level increases, the probability of quitting the job also increases. Whereas the positive coefficient of incentive indicates that respondent which strongly believe incentive is important are more likely to quit the job than other respondents.

The coefficient of income (less than 1500 birr) is positive which can be interpreted as respondent which have monthly income less than 1500 birr are more likely to quit their job than respondents whose monthly income above 5000 birr. There is also significant difference between respondents whose income is between 1501 birr \&2500 birr and respondents whose income is above 5000. Respondents who have monthly income 1501-2500 birr are likely to quit their job than respondents who have income above 5000 birr. And respondents from 2501-3500 income categories are also more likely to quit their job than respondents from above 5000 income category. But there is no statistically significant difference between respondent who have income 3501-4000 birr and respondents who have income above 5000 birr. And also no statistical difference is observed in income category 4000-5000 and above 5000 birr.

Result from qualitative data

Consequence of employees turns over

Respondents were asked about the possible impact of employees turn over by using open ended questions. The results are summarized below.

Employee turnover to come up with poor Work Performance scheme

According to the respondents, Completing annual plan is impossible (Specially the position of the workers who leave their job). Because of this, the workers are forced to cover the position of other workers who leave their job till others will be employee and also the workers who leave their job go without hand in the information about their job. This reduces their efficiency and the performance of the office will also become poor. The workers who are in their position prefer to be like their friends instead of performing their job properly.

Relation of good Working Conditions and Employee turnover

When workers are motivated by giving further education chance, the other workers interest for the job as well also increases. Furthermore the respondents point out the following regard with the impact of having good working condition on employ turn over.

i. Hoping the motivational initiation, the workers will have fruitful efficiency.

ii. If the workers have comfortable condition in their job, they will pay special attention for their work instead of looking for other job.

iii. If conducive working atmosphere is created for the workers, they will do their daily job relaxing their body \& spirit.

iv. The more we motivate the worker; the better will be his/her working efficiency. He/she will be motivated to work in his/her weekends too.

Impact of good Physical Environment on Employee Turnover

The following points are raised by the respondents about the relationship between good physical environments and employ turn over.

i. Most workers leave their job \& employee with a lower salary because of they need conducive work atmosphere.

ii. The reason for workers migration from rural to town is unable to get conducive work atmosphere.

iii. The workers can do their job effectively it the basic needs are fulfilled.

iv. There is no suitable condition, it the worker needs to learn in his/her weekends.

v. If the worker's work place, environment, topography, infrastructure \& technological supplies are available, it completely reduces the migration.

vi. Working in conducive environment means the worker will do another job in his/her free time \& he/she can support his/her self, his family. This doesn't let $\mathrm{him} /$ her look for another place.

Working relations at the Wereda level

Respondent believe that The relation in district is not job relation rather it is friendly relation specially motivational prize and result centered efficiency are given for friends and relatives, so the relationship of efficient worker \& the heads are not tighten. Other points raised are

i. The heads aren't assigned by merit that is why they don't worry the familiarity of the job, even they don't know the job well/they have efficiency shortage

ii. Mostly there is no practical action, it is theoretical.

iii. The government job principles are wrongly interpreted.

iv. Unless they force their professionals, the heads don't satisfy.

v. There is no cooperative work in the same offices. They present different report for same activity.

vi. There is no assigning the worker according to his/her education \& work experience, that is why the districts are becoming a place where workers are practicing their profession instead of working there in stable

vii. There is no strong evaluation \& motivational prize practice in the district level because of this it is impossible to distinguish the most efficient \& not efficient workers.

viii. There is shortage of offices

\section{Discussion}

The main objective of the study is to assess the employee 
turnover rate and cause in the case of Moret and Jiru Wereda. In this study, both quantitative and qualitative research approaches are implemented and due to the purpose a descriptive research design was used and a cross-sectional research survey was also considered. The target populations of the study were all public offices that are found in Moret and Jiru Wereda. Especially, employees of 25 sectors' that are found in the respective Wereda are target population of the study. Then stratified random sampling technique is then adopted to select representative samples from the target population.

In this study, both primary and secondary data were used as source of data. Based on the research objective, English and Amharic version questionnaires were prepared. Three hundred twenty six respondents were approached using probability sampling (stratified random sampling technique). From the 326 survey forms, 306 respondents completed and returned the questionnaire.

The result of this paper indicates that among the respondents $39.9 \%$ of them do not want to quit their current job but majority of them (60.1\%) said they seriously consider quitting their job very often. This result is consistent with Kofi who observed that about $58 \%$ of the employees want to quit their job in Ghana hotel sectors [14].

Moreover, the result of this paper shows that people's educational level does affect their expectations in terms of turnover, possibly because of their different career aspirations. On the one hand, the majority of less educated people know that if they decide to change jobs it will probably be hard for them to find a suitable one since their capabilities are usually not as extensive as more educated employees. In addition, they know that unless they obtain new competencies they will not be able to aspire to better jobs. On the other hand, most employees who are currently obtaining their postgraduate degrees expect to change in the following year or two years, probably because they are becoming more capable of taking higher level jobs and they are likely to hope to get a job that covers the study and monetary investment they made.

In this study monthly income is also found a significant factor of turnover intension and these finding is well supported by Kofi who concludes that salary level can affect employee loyalty to the organization, which is also consistent with [15] and Levine [16]. In other words, when the salary level is not as high as expected, employee work performance might be affected, resulting in reduced contribution to the organization. Respondents of this study also believe that the monthly salary scale which is paid in the district level is very low this makes the well educated workers migrate to other places to find interesting payment.

These paper have also found that satisfaction and incentives to be significantly associated with turnover intensions of employees. The result was also supported by different authors to mention a few lees [17] described that job satisfaction and job characteristics are two important independent variables which cause the turnover of an employee. Lai [18] regarded promotion, pay and reward as independent variable which severely cause the turnover of an employee.

\section{Conclusions}

Because the paper found that the turnover issue is caused by a combination of factors depending on each specific individual, the employers need to be aware of other factors that can affect their employees' decision to change jobs. For instance, offering attractive benefit packages, assigning their employees more challenging responsibilities and allowing them to participate in different areas of the company can contribute to employee retention. In addition, in order to design successful retention programs, employers need to thoroughly understand their employees' needs and expectations because employee turnover is related to the cultural side of organizational problems, which means that employers must work on getting to know their people and why they behave as they do.

Furthermore, the study did not reach a significant number of different industries which might help identify particular industries where turnover is most likely and the reasons for this. This is why future research should be done in a more focused manner in order to make specific analyses to compare, for example, differences between industries in terms of voluntary turnover, identifying trends across job types and positions.

\section{References}

[1] Scott R. Swanson, J. Charlene Davis, (2003) "The relationship of differential loci with perceived quality and behavioral intentions", Journal of Services Marketing, Vol. 17 Issue: 2, pp. 202-219.

[2] Leigh Branham (2005). The 7 Hidden Reasons Employees Leave, business book review, ISBN: 0-8144-0851-6.

[3] Achoui and Mansour (2007). Employee Turnover and Retention Strategies: Evidence from Saudi Companies. International Review of Business Research Papers, Vol. 3 No. 3. pp. 1-16.

[4] Asmamaw Aregeta (2011). Professional employee's turnover and retention practices of Ethiopian public sector Organizations of ministries of finance and economic development. Unpublished Master's Thesis, Addis Ababa University.

[5] Yared Debebe (2007), Staff Turnover in International NonGovernmental Organizations (NGOs).

[6] Solomon Aberra (2007). Skilled Manpower Turnover and Its Management.

[7] R. Renjith Kumar(2011). Turn over issues in the textile industry in Ethiopia: A case of Arba Minch Textile Company, African Journal of Marketing Management Vol. 3(2), pp. 3244.

[8] Kevin MM, Joan LC, Adrian JW (2004). “Organizational change and employee turnover" Personnel Rev. 33 (2):161166. 
[9] Ongori, H. (June 2007). A Review of the Literature on employee turnover. African Journal of Business Management, 049 - 054. 26.

[10] Boxall and Purcell (2011). Strategy and Human Resource Management; third edition ISBN: 9780230579354, Amazon's Book Store.

[11] D. J. Koys(2001). The Effects of Employee Satisfaction, Organizational Citizenship Behavior, and Turnover on Organizational Effectiveness A Unit-Level, Longitudinal Study; Personnel Psychology, Vol. 54, pp. 101-114.

[12] Sekaran, U. (2003), Research methods for business: A skill building approaches (4th Ed.). New York. John Wiley \& Sons Inc.

[13] Graziano, A. M., \& Raulin, M. L. (1997). Research Methods: A process inquiry. New York: Addison Wesley.
[14] Kofi Osei, AduStephen Amponsah and Nicholas Arthur (2015). turnover intention among categories of staff in the hotel industry in Ghana: a case of Sekondi-Takoradi metropolis, PRA Paper No. 68536.

[15] Folger, R. and Konovsky, M. A. (1989) Effects of Procedural and Distributive Justice Reactions to Pay Raise Decisions. Academy of Management Journal, 32, 115-130.

[16] Jiang, J., Levine, M. (1993). Binding affinities and cooperative interactions with bHLH activators delimit threshold responses to the dorsal gradient morphogen. Cell 72(5): $741-752$.

[17] Lee, T. (1988). How job dissatisfaction leads to employee turnover. Journal of Business and Psychology, 2(3).

[18] Lai, C. (2009). Motivating employees through incentive programs. Jyvaskyla University of Applied Science. 